\title{
A Study on Airbnb's Trust Mechanism and the Effects of Cultural Values-Based on a Survey of Chinese Consumers
}

\author{
Xiaojun $\mathrm{Wu}{ }^{*}+\stackrel{+}{(\mathbb{B})}$ and Jiabin Shen ${ }^{\dagger}$ \\ Department of Event Economics and Tourism Management, Glorious Sun School of Business and Management, \\ Donghua University, Shanghai 200051, China; shenjiabin@dhu.edu.cn \\ * Correspondence: xjunwu@dhu.edu.cn; Tel.: +86-21-62379673 \\ + These authors contributed equally to this work.
}

Received: 1 July 2018; Accepted: 23 August 2018; Published: 27 August 2018

\begin{abstract}
A sharing economy is developing rapidly worldwide, especially in China. Trust has been considered as a crucial factor in facilitating the practice of the short-term rental business, where hosts and renters are strangers. However, not only has the inherent trust-building mechanism of this newly emerged business model not been fully explored, but how cultural values affect the trust-building path also remains unknown. This study proposes a model of the trust-building mechanism in the sharing economy platforms, with three central modes-institutional trust, product trust, and interpersonal trust - and introduces national cultural values dimensions at the individual level as moderators to explore the impact on the inherent mechanism of trust-building on Airbnb. The data collected from 210 Chinese Airbnb consumers by survey provides support for the proposed structural equation model. The results show that institutional trust has a positive influence on product trust and interpersonal trust, and that product trust has a positive influence on interpersonal trust as well. For the moderating effect of cultural values, the relationship between the institutional trust and product trust is regulated by power distance (PDI), individualism (IDV), uncertainty avoidance (UAI), and long-term orientation (LTO), while the relationship between product trust and interpersonal trust is regulated by PDI, IDV, and UAI. This paper indicates that in order to foster trust in the sharing economy, practitioners should enhance institutional trust, product trust, and interpersonal trust synchronously, as these three modes of trust are positively inter-related; they must also be sensitive to local cultural value dispositions when conduct sharing business internationally.
\end{abstract}

Keywords: Sharing economy; trust mechanism; Airbnb; cultural values

\section{Introduction}

'Sharing' refers to the behavior of an individual to use, possess, or enjoy something with others. It is a term that has been used by human society for a long time, and the sharing behavior will generate and reproduce social relations [1]. In recent years, along with the development of information communication technology, the rising of consumer awareness regarding sustainability, and the increasing number of collaborative web communities [2], new forms of sharing behaviors have emerged by providing individuals with idle resources to others via the internet, so as to efficiently make use of the resources and to create new value, thus forming a kind of innovative economic model — the 'sharing economy'. The big difference between this new form of sharing economy and traditional sharing patterns is that the new form of sharing does not occur between kin family members or in acquaintance communities [1], but rather as a form of market in which strangers exchange goods and services. Rifkin (2014) [3] stated that the sharing economy is more dependent on social trust than on invisible market forces. 
Furthermore, one of the major reasons that the sharing economy has attracted extensive attention is that this new model is expected to have the potential to provide a new pathway to sustainability [4-6]. Most advocates of the sharing economy believe that the sharing economy can make the best use of things and can reduce the impact on the ecological environment [6,7]. In many cases, the environmental effects of the sharing economy are certain, because choosing to share rather than buy new goods and services (e.g., hotels and taxis) will result in fewer ecological footprints [8,9]. However, the uncertainty regarding the social and economic sustainability of the sharing economy has hovered $[10,11]$ ever since its birth. The debates over its negative impacts never cease (e.g., noise and disturbance on short-rental agglomerated neighborhoods, as well as unfair competition and threats to the conventional industry, such as taxi services, hotels, and inadequate labor protection). The negative news regarding unsafe riding or living in a shared property [11-13] have increased doubts regarding the sustainability of the sharing economy model. Whether the sharing economy can be a transition to a more sustainable economic model that is based on efficient the use of idle resources and a reduction of the negative externalities generated by such businesses [14] has become a controversial topic. Many scholars believed that the ability to build lasting trust would be a determinant factor for sustaining the sharing economy model $[5,15]$, and that trust-building is vital to the long-term sustainable development of short-term rental practices. Therefore, for both researchers and practitioners, it is important to comprehend the trust-building mechanisms in order to alleviate the trust tension [16].

In fact, as a new model that combines economic rationality, technical infrastructure, and cultural appeal $[17,18]$, the sharing economy has changed the world by a significant growth in scale and remarkable popularity in travelling, shopping, and loaning activities in recent years. PricewaterhouseCoopers predicted that the global sharing economy output would reach $\$ 335$ billion by 2025, and its industry scale and development potential will be huge [19]. One of the most outstanding sharing economy platforms is Airbnb, which is a service-oriented business that connects travelers to hosts who are renting out their properties to short-term residents. Founded in 2008, Airbnb has expanded its business very quickly, and by June 2018, it has provided over 5 million listings in over 191 countries, and accommodates over 300 million guests living in the rooms that Airbnb offers. Moreover, after about eight years of cultivation, China has become the company's second-largest growth market in the world [20].

This rapid growth of the short-rental business in China relates to a favorable regulatory environment. The Chinese government has been very supportive of the healthy development of the sharing economy since 2016 [21]. In March 2018, the state council of China officially supported that urban and rural residents may, according to law, use their own houses to engage in tourist accommodation operations [22]. Compared with the tightening regulations of car-sharing and the short-rental business in other countries (e.g., Japan, Spain, and the United States) $[23,24]$, the environment for developing the sharing economy is very friendly in China. Moreover, China is attempting to control the negative impact of this new economic model by improving the oversight of data security and participants' qualification reviews. Therefore, it is not surprising to see the exponential growth trend of Airbnb in China. As of the end of July 2017, a total of 8.6 million travelers from China have used Airbnb services in foreign destinations, and half of Airbnb users in Asia are Chinese. Domestic travel is also buoyant in China, pushing the number of rooms available for rent on Airbnb in China to 150,000 at the end of 2017, double that of 2016 [20].

To some extent, the achievement of the sharing economy stems from some values that consumers want to achieve, such as sharing trust and cooperation. Moreover, the sharing economy rose in the Western society; its trading mechanism is anchored in mutual trust between individuals, which is closely associated with the relatively healthy endowments of social capital and high-trust social relations in the societies [25]. While the establishment of trust is dependent upon shared motives, values, beliefs, identities, and interpretations of the meanings that guide an individual's behavior and beliefs in a specific culture [26], Airbnb would face more obstacles and challenges for trust issues in China. As China has been labeled as a low-trust nation in some cross-cultural studies $[25,27,28]$, Chinese 
people are assumed to have very different cultural value tendencies in social relations compared with Westerners.

There are emerging studies on the trust issues of sharing economy platforms in academia $[6,7,15,29-31]$, which explore the factors that impact the trustworthiness of the business. However, the specific effect of the cultural values' attributes that are considered important for effective trust-building in the sharing economy has been less studied. To bridge the research gap, this article explores the inherent relationship of Airbnb's trust-building mechanism and the moderating effects of cultural value dispositions of Chinese consumers on the trust mechanism, based on a structured model and questionnaire survey. The aim is to understand the trust-building mechanisms of the sharing economy and to provide an empirical study of the Chinese market.

This study contributes to the literature on the trust-building mechanism of the sharing economy research in the following three ways. To the best of our knowledge, this study is the first to examine the effects of the cultural value dispositions of Airbnb's consumers at the individual-level on the trust-building mechanism of the sharing economy. Secondly, this paper contributes to the existing literature by incorporating Zucker's trust production theory [32] and the sharing economy's features, to develop the model and the specific scales of measuring the three modes of trust-building (institutional trust, interpersonal trust, and product trust) within the Airbnb context. Thirdly, this paper provides an empirical study of the perception of Chinese users towards Airbnb and their cultural tendencies' influence on the trust-building mechanism, so as to enrich the comprehension of non-Western users' perception of the sharing economy.

The rest of this paper is organized as follows. Section 2 presents reviews of the key literature on the trust-building issues in the online business context and the sharing economy context, as well as the study of the cultural factors' influence on trust. In Section 3, a trust-building model is used as the foundation for the theoretical model of the study. Moreover, the individual-level conceptualization of national cultural values is incorporated into the model as moderators of the trust-building mechanism and specific hypotheses are developed. Section 4 discusses the data and the methodology employed in this paper. Section 5 presents the key results of the study. Section 6 is the discussion part of the findings, followed by Section 7, which summarizes the conclusions and the limitations of our research.

\section{Literature Review}

\subsection{The Sharing Economy and Airbnb}

The development of internet technology promotes the generation of the sharing economy [6]. Recent changes in the global economic climate, especially the financial crisis of 2008, have intensified this phenomenon [33]. Although this new model lacks a widely accepted and precise definition and goes by different names; the terms 'collaborative consumption', 'mesh', 'peer to peer (P2P) economy', and 'sharing economy' are all used to describe this P2P sharing of underutilized goods and services, and it has radically changed the way people produce, consume, interact, and live, which leads to the gradual weakening and death of ownership [1,7]. For example, Botsman and Rogers (2010) are the first to use the term 'collaborative consumption' to name this new internet-based business model; they think that this model had the ability to save money or make money, provide a new consumption experience, reduce ecological footprints and carbon emissions, and strengthen social ties [5]. Gansky (2010) uses 'mesh' to describe the sharing economy, believing that it is essentially built on the network-based sharing platform, and that the participants' purpose is to use rather than own [17]. Schor (2015) identifies three characteristics to help define the sharing economy, the promotion of strangers' sharing ability, the dependence of digital technology, and the participation of consumers with high cultural capital [7]. Even though there is no definitive definition of the sharing economy, scholars and practitioners believe that this model would transform our current social economic system by allowing individuals, communities, organizations, and policy makers to rethink the way people live, connect, generate values, and sustain themselves $[1,7,18]$. 
Researchers have also investigated why the sharing behavior can become a phenomenon that changes the existing economic order on such a large scale. Three major reasons for this are (1) the change of values, concerns about the environmental quality, and sense of community has significantly increased [17,34]; (2) cost savings [5,35]; and (3) internet technology has greatly reduced the cost of people's sharing, such as location based service (LBS) and social networking platform (SNS), which has made the sharing channel more real-time and accurate [7,33].

Because of its fundamental cultural, economic, and organizational implications $[4,7,20,35,36]$, researchers have examined how users participate in this model, how to make this model sustainable [4], and how the sharing economy impacts the participants [36]. Researchers have found that the complexity of the model and the many risks it entails [37] is one of the major problems in the real implementation of the sharing economy, which lies in people's mutual trust and integrity [36].

This new model has flourished in various sectors of our society, such as collaborative production, financing, and consumption [33], and has introduced new players that have gained some prominence in many fields, such as Uber and Airbnb. Among all of the industries, tourism and hospitality can be considered as one of the pioneering sectors as a result of its growth, as the sharing economy allows for tourists and residents to share their homes, automobiles, meals, and expert local knowledge [37,38]. Moreover, as one of the most prominent examples of the sharing economy, Airbnb has drawn intense attention from the academia $[10,29,31,39]$. Many scholars who have investigated the reasons for the popularity of Airbnb agree that factors like the sustainability (e.g., social and environmental responsibility), community (e.g., community interaction), and economic benefits (e.g., lower cost) are the main attractions appealing to people to participate in Airbnb [36,40]. However, it is also "a platform with the tax evasion, legal loopholes, and ignoring health and safety standards" in protesters' eyes $[12,13]$. The rapid expansion of Airbnb has caused critics to worry about the health and security issues of this P2P short-rental platform. Therefore, no matter which motivation is behind the sharing, trust is the key in order to sustain the sharing economy's growth and success [1]. The trust-building mechanism of Airbnb is worthy of further investigation.

\subsection{Trust in E-Commerce and Trust in the Sharing Economy}

As an important concept of social science and psychology, the trust theory has been studied deeply by many scholars, but it has not been defined uniformly [41-43]. It is generally believed that trust is an important factor in many social and commercial interactions involving uncertainty and dependency [44-46].

While, in environments where risk and uncertainty, or a combination of both, exist, trust plays a decisive role in overcoming, proving, or restraining ancillary consequences [47,48]. This is especially true for the socially distant relationships (for instance, in computer-mediated environments), as a result of the increased complexity and uncertainty $[49,50]$. In the e-commerce market, where not everything is governed by rules and regulations, extra factors such as online payment security, the reliability of companies, and privacy policies [47], increase the uncertainty of transactions and make trust very important in order to facilitate online interactions [44,47].

"To share is to trust" [5]; trust is regarded as an invisible currency [1] in the sharing economy, where participants have to trust strangers to share goods or properties. Trust-building among buyers toward sellers is more critical than that of the traditional online business. The sharing platforms play a mediating role, eliminating information asymmetry between the users and providing a good environment for both parties so as to build trust. Specific cultural environments and economic environments are also important factors for the development of the sharing economy [30].

Compared with traditional e-commerce practices, the picture is more complex for the sharing economy. Firstly, it involves the temporary possession of private property in an intermediary framework [51], and the ownership of the shared good/property is not transferred. Secondly, the sharing economy users engage in interactions with multiple parties, usually the platform operator and another private individual [52]. Moreover, it often involves close physical interactions between the two 
parties in order to conduct business, in addition to the virtual world transactions on the platforms. In a traditional e-commerce context, online consumer reviews or rating scores are often used as important elements to build and enhance trust by researchers [15]. However, in the sharing economy, such as in Airbnb, the customer rating tends to homogeneity, with extremely low variance, and is not valuable enough to build trust $[10,29]$. Consequently, to facilitate better trust-building in P2P sharing platforms, other relevant information about hosts, including host photographs [29], need to be shared to decrease information asymmetry and to reduce the potential displeasure when strangers participate in the sharing economy [53]. The platform, however, acts as a broker and a mediator between both of the market sides, and may also appear to be trustworthy or not. In this context, the trust may be affected by privacy concerns [54], or the quality of website [55]. Moreover, even the product itself may have to face up to trust concerns [56], particularly as, typically, no official quality standards, official regulations, or inspections are in place for this rather new model [52].

Most researchers construct a model of trust in the sharing economy from two market perspectives (consumers and providers). For example, Parves Karmal (2016) investigates the factors that affect people's trust and willingness to participate in the sharing economy [57]. Christoph Mittendorf (2016) investigates the trust formation in the sharing economy from the provider's perspective [54]. Wu et al. (2017) also adopt the providers' perspective to identify the attributes of the host, which are perceived as trustworthy and affect the renters' purchase decisions on a short-rental P2P platform [15]. However, very few researchers have constructed a conceptual model by incorporating all of the relevant elements. Xie et al. (2016) propose that the formation of trust in a sharing economic platform must include all of the following factors, including the consumers' needs and familiarity, platform's guarantee policies, participants' attributes, and the product and feedback [58]. Hawlitschek et al. (2016) explore how three different targets of trust affect the participant's intention, and outline an inclusive conceptual model to describe how trust influences both the consumers' and suppliers' intentions to engage in the sharing economy [52]. However, this study did not analyze how these three different targets of trust correlate with each other.

We contend that the 3P's (trust in peer, platform, and product) of the trust-building perspective should be included in constructing a model of the trust mechanism of the sharing economy. Zucker's trust production theory [32], which proposes three central modes of trust production (institutional-based, process-based, and characteristic-based), sheds light on our model construction. We agree with Zucker's theory of trust production, but we assume that the three modes are not independent; on the contrary, there is an interactive and complementary relationship between each of the two modes in the trust-building mechanism. Therefore, we employ Zucker's trust production model as the basic model to explore the internal relationship of the trust mechanism within the short-rental business context. The first is institutional trust. It includes a series of design patterns and mechanisms established by platform operators to build and maintain trust among two-sided users, including rating policy and mutual review schemes, and verification mechanisms [15], which could drive adoption of more social and economic sustainable practices because the platform operators seek a favorable organizational reputation [59]. The second is trust in the product. As in the sharing economy, the products are usually virtually presented, this mode of trust describes how the product is perceived as reliable by the consumers [52]. In the short-term rental business, the platform can guide the vendors to provide more details about the function and features of the apartment to help consumers build up trust for the product. The third mode of trust is interpersonal trust. As in the sharing Economy, the vendor's and customer's role is taken by private individuals, the quality of interaction between these two private individual parties would be determinant on whether an agreement can be achieved. The consumers would need to be more convinced by good communication with the vendors, which can decrease information asymmetry, and the vendors should pay more attention to interacting with the consumers so as to show more personal information in order to build their online reputation [53]. 


\subsection{Cultural Values and Trust}

The establishment of trust is dependent upon shared motives, values, beliefs, and identities, but the interpretations of the meanings that guide an individual's behavior and beliefs differ between specific cultures [26]. Among the many definitions of culture, we adopt Hofstede's definition, "culture is the collective programming of the mind that distinguishes the members of one group or category of people from another" [60]. Beginning in the 1950s, social scholars developed various classification systems for the universal national cultural dimension theory [26,61]. Since the 1970s, cultural scholars have applied empirical methodologies to verify the cultural dimensions [60-63]. The most popular cultural dimension theory was proposed by Geert Hofstede, who identified five dimensions of culture that help explain how and why people from different cultures differ [60].

The theoretical research suggests that culture and trust are interrelated [61], and that some empirical studies examine how the dimensions of national culture impact trust in the e-commerce environment. Yagamishi (1988) reveals that countries like China and South Korea are low-trust societies, while Japan, Germany, and the United States are high-trust societies, because of their cultural influence [64]. Some researchers perform comparative cross-cultural studies between different countries. For example, Hallikainen et al. (2018) applied Hofstede's cultural theory to explain the variance in consumer trust in e-commerce between China and Finland, finding that the disposition to trust is a highly significant predictor of the perceived trustworthiness of an online store [65]. Other studies have found that the national culture can affect the consumers' trust in e-commerce situations [66-68]. Yoon (2009) examines how specific dimensions of the national culture influence trust, for example. Yoon collected data in China to investigate the moderating effect of power distance, individualism, uncertainty avoidance, and long-term orientation on the relationship between trust and the consumers' purchase intention [67]. However, the majority of existing studies have been conducted in Western countries, and only consider one or two dimensions of the national culture influence on trust [69].

Previous studies often use the Hofstede cultural value scores to identify the characteristics of cultures at the nation level [70], while some researchers have recognized that value orientations can be applied to reflect the characteristics of individuals [67]. Srite et al. (2006) assess the national cultural value traits at the individual level of analysis, and incorporate these espoused national cultural values into the model as moderators of the technology acceptance relationship [71].

To our surprise, empirical research validating the impact of cultural value dispositions on the trust-building mechanism in the sharing economy context is scarce, which is lagging behind the international practice of this newly emerged model. Consequently, we aim to respond to this research gap by exploring how the five Hofstede's culture dimensions influence customers' perceived trustworthiness of Airbnb's trust mechanism, by incorporating individual's cultural value tendency as moderators into the trust-production model. This study also adds to the existing literature by providing empirical data about the moderating effect of the cultural dispositions of customers on trust-building for Airbnb, using data collected in China.

\section{Research Model and Hypotheses}

\subsection{Research Model}

To explore the effects of culture value dispositions on the trust-building mechanism of the sharing economy, the research model includes both the Zucker's trust-producing model together with the variables of demographics, and espoused Hofstede's cultural dimensions of power distance (PDI), individualism (IDV), masculinity (MAS), uncertainty avoidance (UAI), and long-term orientation (LTO) as moderators in the model. As Figure 1 shows, 'institutional trust', 'interpersonal trust', and 'product trust' are the three aspects of trust in this model, and the arrows in the continuous line linking them represent the hypotheses of the interrelationship between those three constructs. The 'cultural dimensions' and 'demographics characteristics' are moderators in this model, and the arrows in the 
dotted line represent the hypothesis of moderating the impact on the relationship between those three trust constructs. The details of the hypotheses are elaborated on in Section 3.2.

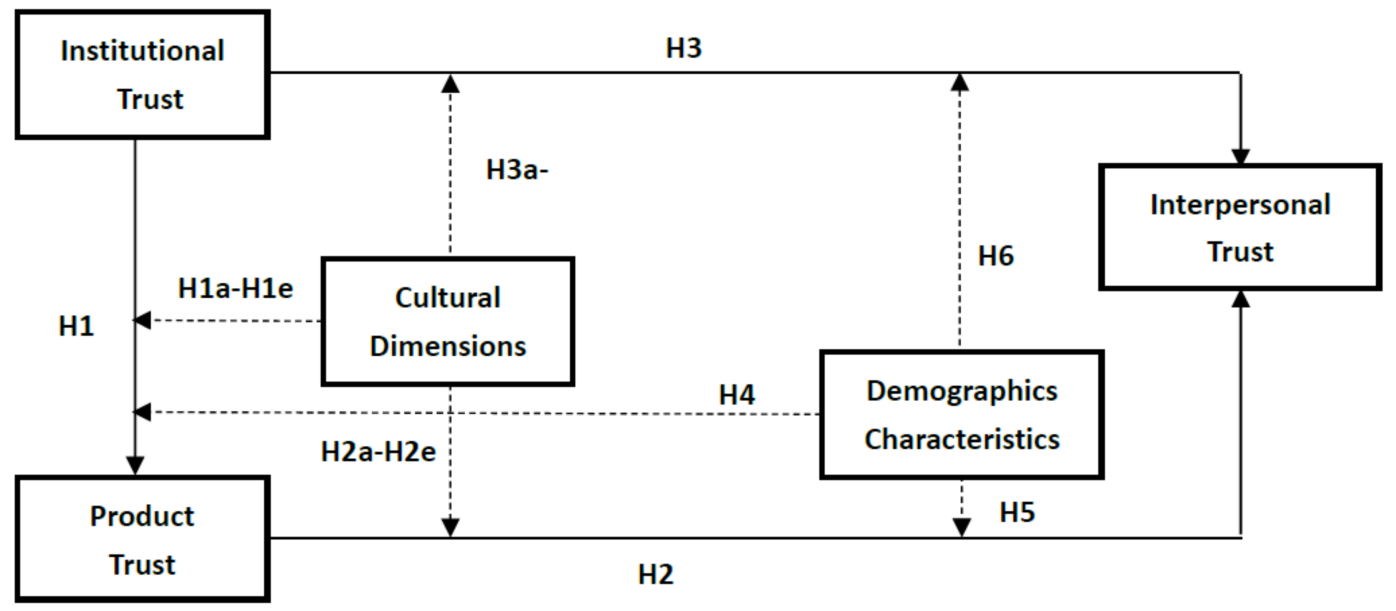

Figure 1. Research model.

\subsection{Hypotheses}

Based on the three modes of trust-production [32] and the trust constructs of the sharing economy platform [52,58], we propose three major constructs of trust-building, namely, institutional trust (IT), interpersonal trust (IPT), and product trust (PT). Furthermore, we subdivide them into 18 specific categories, according to the characteristics of each category, after reading the related literature on the evaluation system of the home-stay facilities, as is shown in Table 1 below.

Table 1. The Measurement of the constructs and the sources.

\begin{tabular}{|c|c|c|}
\hline Constructs & Categories & References \\
\hline Institutional trust & $\begin{array}{l}\text { The reputation and quality of the website } \\
\text { Description of the listing } \\
\text { Risk perception of the website } \\
\text { Structural assurance of the website }\end{array}$ & {$[32,44,49,58] ;$} \\
\hline Interpersonal trust & $\begin{array}{l}\text { The hosts' ability to fulfill service commitment } \\
\text { The host-guest principle of not leaking mutual privacy } \\
\text { The host's courteous manners } \\
\text { The timeliness of the host's response to problems } \\
\text { The host's ability of initiative care for renters } \\
\text { The realization of social values of host and guest }\end{array}$ & {$[58,72-74] ;$} \\
\hline Product trust & $\begin{array}{l}\text { Decoration styles } \\
\text { Comfort level of rooms } \\
\text { Well-equipped facilities in rooms } \\
\text { Daily cleaning } \\
\text { Sound insulation effect of rooms } \\
\text { Travel convenience } \\
\text { Neighborhood environment } \\
\text { Surrounding tourist attractions }\end{array}$ & {$[58,75-78]$} \\
\hline Cultural dimensions & $\begin{array}{l}\text { Power distance } \\
\text { Individualism } \\
\text { Masculinity } \\
\text { Uncertainty avoidance } \\
\text { Long-term orientation }\end{array}$ & {$[60,71]$} \\
\hline
\end{tabular}




\subsubsection{Institutional Trust (IT)}

Zucker [32] points out that institutional trust is related to the current social structure and is based on the specific attributes or intermediary mechanisms of individuals or enterprises. Pavlou et al. [49] believe that institutional trust is the institutional norm in the society. The parties concerned will weigh the risks and opportunity costs caused by untrustworthiness, and rationally maintain good faith behaviors. This is an impersonal trust that can be extended to broader economic transactions, including short-term rental deals. To ensure trust and security, Airbnb issued a set of standards and expectations for all of the hosts and renters, and formulated a series of non-discrimination, privacy protection, and refund policies. For example, as a renter, you can check the personal profile and comments of potential hosts before making a reservation. As a host, you can read the information and comments of the potential renters, as well as check the relevant social accounts and references $[49,79]$.

\subsubsection{Interpersonal Trust (IPT)}

Interpersonal trust refers to characteristic-based trust, as proposed by Zucker. In his opinion, the generation of characteristic trust is based on the person/individual. The essence of interpersonal trust is the reflection of the individual characteristic difference, which has an important influence on the cooperation mechanism and social life. In the short-term rental platforms, interpersonal trust mainly focuses on the renters' trust in the hosts, which is mirrored in the interaction between hosts and guests, and is highly related to the quality of communication [72,73].

\subsubsection{Product Trust (PT)}

Product trust refers to the process-based trust proposed by Zucker. In his opinion, process trust in the economic society mainly comes from the past or expected product transactions. In the short-term rental business context, product trust is essentially a contractual relationship between consumers and Airbnb, and it also brings a sense of security and trust to consumers. At the same time, considering different types of the evaluation index of home stay facilities, product trust will stimulate consumers to repurchase home stay resources and enhance brand loyalty $[75,76]$.

\subsubsection{Cultural Values}

According to Hofstede's cross-cultural theory, there are five cultural dimensions [60].

Power distance (PDI): refers to the recognition of members of the society on the class difference caused by power and wealth. The power distance gap reflects the concentration degree and dictatorship degree of power in the society.

Individualism (IDV): the degree to which individuals are integrated into groups.

Masculinity (MAS): the degree to which a society emphasizes traditional masculine values (such as success, achievement, and ambition).

Uncertainty avoidance (UAI): the degree to which people feel threatened by ambiguous situations and have created beliefs that try to avoid it.

Long-term orientations (LTO): shows the degree of preference for long-term benefits. A long-term orientation society emphasizes behavior, such as thrift or perseverance, intended to secure future rewards.

To explore the relationships of institutional trust, interpersonal trust and product trust, we regard cultural factors and demographics characteristics as moderators for further research. The hypotheses are presented in Table 2, and the corresponding test will be carried out in the following pages, based on the pertinent literature and the rule of thumb. 
Table 2. Hypotheses when cultural factors and demographics are moderators.

\begin{tabular}{|c|c|}
\hline No. & Hypotheses \\
\hline H1 & Institutional trust has a positive and significant impact on product trust. \\
\hline H1a & $\begin{array}{l}\text { The relationships between institutional trust and product trust are adjusted by power distance. The higher the power } \\
\text { distance is, the weaker the influence of institutional trust on product trust will be. }\end{array}$ \\
\hline H1b & $\begin{array}{l}\text { The relationships between institutional trust and product trust are adjusted by individualism. The higher the } \\
\text { individualism is, the weaker the influence of institutional trust on product trust will be. }\end{array}$ \\
\hline H1c & $\begin{array}{l}\text { The relationships between institutional trust and product trust are adjusted by uncertainty avoidance. The higher the } \\
\text { uncertainty avoidance is, the weaker the influence of institutional trust on product trust will be. }\end{array}$ \\
\hline H1d & $\begin{array}{l}\text { The relationships between institutional trust and product trust are adjusted by long-term orientation. The higher the } \\
\text { long-term orientation is, the stronger the influence of institutional trust on product trust will be. }\end{array}$ \\
\hline H1e & $\begin{array}{l}\text { The relationships between institutional trust and product trust are adjusted by masculinity. The higher the masculinity } \\
\text { is, the weaker the influence of institutional trust on product trust will be. }\end{array}$ \\
\hline $\mathrm{H} 2$ & Product trust has a positive and significant impact on interpersonal trust. \\
\hline $\mathrm{H} 2 \mathrm{a}$ & $\begin{array}{l}\text { The relationships between product trust and interpersonal trust are adjusted by power distance. The higher power } \\
\text { distance is, the weaker the influence between product trust and interpersonal trust will be. }\end{array}$ \\
\hline $\mathrm{H} 2 \mathrm{~b}$ & $\begin{array}{l}\text { The relationships between product trust and interpersonal trust are adjusted by individualism. The higher } \\
\text { individualism is, the weaker the influence between product trust and interpersonal trust will be. }\end{array}$ \\
\hline $\mathrm{H} 2 \mathrm{c}$ & $\begin{array}{l}\text { The relationships between product trust and interpersonal trust are adjusted by uncertainty avoidance. The higher } \\
\text { uncertainty avoidance is, the weaker the influence between product trust and interpersonal trust will be. }\end{array}$ \\
\hline $\mathrm{H} 2 \mathrm{~d}$ & $\begin{array}{l}\text { The relationships between product trust and interpersonal trust are adjusted by long-term orientation. The higher } \\
\text { long-term orientation is, the stronger the influence between product trust and interpersonal trust will be. }\end{array}$ \\
\hline $\mathrm{H} 2 \mathrm{e}$ & $\begin{array}{l}\text { The relationships between product trust and interpersonal trust are adjusted by masculinity. The higher masculinity is, } \\
\text { the weaker the influence between product trust and interpersonal trust will be. }\end{array}$ \\
\hline H3 & Institutional trust has a positive and significant impact on interpersonal trust. \\
\hline H3а & $\begin{array}{l}\text { The relationships between institutional trust and interpersonal trust are adjusted by power distance. The higher the } \\
\text { power distance is, the weaker the influence of institutional trust on interpersonal trust will be. }\end{array}$ \\
\hline $\mathrm{H} 3 \mathrm{~b}$ & $\begin{array}{l}\text { The relationships between institutional trust and interpersonal trust are adjusted by individualism. The higher the } \\
\text { individualism is, the weaker the influence of institutional trust on interpersonal trust will be. }\end{array}$ \\
\hline $\mathrm{H} 3 \mathrm{c}$ & $\begin{array}{l}\text { The relationships between institutional trust and interpersonal trust are adjusted by uncertainty avoidance. The higher } \\
\text { the uncertainty avoidance is, the weaker the influence of institutional trust on interpersonal trust will be. }\end{array}$ \\
\hline H3d & $\begin{array}{l}\text { The relationships between institutional trust and interpersonal trust are adjusted by long-term orientation. The higher } \\
\text { the long-term orientation is, the stronger the influence of institutional trust on interpersonal trust will be. }\end{array}$ \\
\hline H3e & $\begin{array}{l}\text { The relationships between institutional trust and interpersonal trust are adjusted by masculinity. The higher the } \\
\text { masculinity is, the weaker the influence of institutional trust on interpersonal trust will be. }\end{array}$ \\
\hline H4 & $\begin{array}{l}\text { The relationships between institutional trust and product trust are significantly different regarding the demographics } \\
\text { of consumers interviewed. }\end{array}$ \\
\hline H5 & $\begin{array}{l}\text { The relationships between product trust and interpersonal trust are significantly different regarding the demographics } \\
\text { of consumers interviewed. }\end{array}$ \\
\hline H6 & $\begin{array}{l}\text { The relationships between institutional trust and interpersonal trust are significantly different regarding the } \\
\text { demographics of consumers interviewed. }\end{array}$ \\
\hline
\end{tabular}

\section{Research Methodology}

This study empirically explores the validity of the trust-building model of the sharing economy that incorporates three modes of trust, originally developed for the traditional transactions in developed countries' research, for use in the sharing economy context in an emerging market. China was chosen as our survey area to investigate the effect of the national cultural dispositions on the trust-building mechanism. For this purpose, we employed the approach proposed by Srite et al. (2006) to assess the cultural dispositions at the individual level, using Hofstede's cultural dimensions [71].

There are many latent variables in this research that could not be measured directly, such as the IT/IPT/PT and cultural dimensions, so we used the observed variables to measure those variables indirectly. To improve the accuracy of the overall measurement, we used a structural equation model (SEM) to analyze our research, as it can eliminate random measurement errors that occur in analyzing the structural relationship between the latent variables, and can provide the most comprehensive and appropriate analysis for studying the mediating effect [80]. The multi-group analysis was adopted to 
verify the hypothesis of whether the interviewees of different demographic characteristics and cultural value dispositions demonstrated significant differences in influencing relationships.

The questionnaire used for the data collection consisted of two parts, of 29 questions. A five-point Likert scale ranging from 1 (strongly disagree) to 5 (strongly agree) was used to measure the various constructs of the model. As shown in Table 1, the measurements of the items for IT, IPT, and PT were adapted from studies by Zucker, Gefen et al., and Pavlou and Xie [32,47,49,58]. The items for PDI, IDV, MAS, UAI, and LTO were adapted from Srite et al., and Yoon's $[67,71]$ studies. A pilot test of the measures was conducted among university students in China, and the phrasing of the items was modified after obtaining the results from the pilot test. Appendix A illustrates all of the items used in the study.

\subsection{Survey Administration}

It was difficult to approach consumers who had experience with using Airbnb. Therefore, we used the Sojump website to develop the online questionnaire and adopted the following two ways to distribute the questionnaires from April to May in 2017: (1) searching for microblog-users who have posted Airbnb related microblogs via Sina-Weibo (one of the top microblog platforms in China), and inviting them to participate in the survey by sending the URL link of the on-line survey via private messages, and (2) posting URL (Universal Resource Locator) links of the on-line survey in several university student groups and MBA (Master of Business Administration) student groups on Wechat, and inviting all of the potential qualified correspondents to fill in the questionnaire. A screening question was set at the beginning of the questionnaire to exclude those who have not used Airbnb. The respondents were offered incentives in the form of a monetary award of $¥ 50$, to be raffled among the participants. All of the participants were assured that the results would be reported only in aggregate and that their anonymity would be assured.

Finally, via the first channel, 650 private messages were sent out, with a response rate of $19.3 \%$ (126), and 17 questionnaires were invalid. For the second channel, we received 122 responses, and 21 questionnaires were invalid. Thus, we received 210 valid responses, which resulted in a $27.2 \%$ response rate. The specific demographic information is shown in Table 3.

Table 3. Descriptive statistics of respondents' characteristics.

\begin{tabular}{cccc}
\hline Variables & Categories & Frequency & Percentage \\
\hline \multirow{2}{*}{ Gender } & Men & 63 & $30.00 \%$ \\
& Women & 147 & $70.00 \%$ \\
Age & $\leq 25$ & 140 & $66.67 \%$ \\
& $26-35$ & 51 & $24.29 \%$ \\
& $36-45$ & 17 & $8.09 \%$ \\
Education & $\geq 45$ & 2 & $0.95 \%$ \\
& College degree or below & 10 & $4.76 \%$ \\
& Bachelor candidates and & 132 & $62.86 \%$ \\
& bachelor & & \\
& Master & 65 & $30.95 \%$ \\
Monthly disposable & Doctor & 3 & $1.43 \%$ \\
income (yuan) & $\leq 1000$ & 21 & $10.00 \%$ \\
& $1001-3000$ & 91 & $43.33 \%$ \\
& $3001-5000$ & 58 & $27.62 \%$ \\
& $\geq 5000$ & 40 & $19.05 \%$ \\
\hline
\end{tabular}

\subsection{The Descriptive Statistical Analyses of the Respondents}

From Table 3, we learn that female respondents account for $70 \%$ of the total samples, which is consistent with the 2017 Report on The Trend of Sharing Lodging Consumption in China, that women are the main force of sharing lodging consumption. Regarding age, $91 \%$ of the respondents 
are from the post-1980s and post-1990s generation. The booming of the sharing economy platforms is mainly attributed to the rise of millennial consumers who are the major participants and the main consumption force of the sharing economy [81]. Moreover, education data indicates that most of the respondents have a bachelors, masters, or doctoral degree, which reveals that the sharing economy is more popular with the well-educated consumers.

\subsection{The Descriptive Statistical Analyses of the Constructs}

Table 4 shows the mean scores and standard deviations of the constructs of the cultural values. As we used a 5-point Likert-style score to measure the items, we got mean score ranges from 2.567 (MAS) to 3.602 (LTO). Comparing the mean scores of each cultural dimension, we got the following sequence for the score of each cultural dimension, LTO $>$ IDV $>$ PDI $>$ UAI $>$ MAS, which is in agreement with the scores on the cultural dimensions of China reported by Hofstede [82].

Table 4. Descriptive statistics of culture dimensions scale.

\begin{tabular}{ccc}
\hline Construct & Mean (Std.) & Hofstede Score (China) \\
\hline Power distance & $3.09(0.605)$ & 80 \\
Uncertainty avoidance & $2.907(0.851)$ & 60 \\
Individualism & $3.383(0.665)$ & 21 \\
Masculinity & $2.567(0.658)$ & 51 \\
Long-term orientation & $3.602(0.844)$ & 118 \\
\hline
\end{tabular}

As with the scales of the constructs for the Airbnb trust-building mechanism, the top three survey items are "I care about the hygiene level in the room", "I appreciate it when the host is kind and polite", and "I will select a house with good public security around", while "hosts and renters are supposed to be honest with their privacy" scores the least, indicating that the majority of respondents are conservative in personal privacy. Comparing the mean score of each construct, the perceptions of the importance of trust constructs follow the sequence of PT $>$ IPT $>$ IT, as Table 5 shows.

Table 5. Descriptive statistics of trust construct data.

\begin{tabular}{cc}
\hline Construct & Mean (Std.) of the Construct \\
\hline Institutional trust & $3.43(0.538)$ \\
Interpersonal trust & $3.67(0.535)$ \\
Product trust & $4.02(0.762)$ \\
\hline
\end{tabular}

\section{Results}

\subsection{Validity Analysis and Reliability Analysis}

To determine the validity of the data, we conducted the Kaiser-Meyer-Olkin (KMO) and Bartlett's sphericity tests. The KMO of the questionnaire is equal to 0.944 , which is greater than the recommended value of 0.6. Also, the Bartlett's sphericity test approximates chi-square $=2970.857$, and under the condition of 171 degrees of freedom, Sig. $=0.000<$ significance level 0.05 , indicating there are common factors in the correlation matrix. Both test results agree with the index, suggesting that there is good construction validity between the original variables. To determine the reliability of the data, the Cronbach $\alpha$ coefficient, which verifies the internal consistency regarding each study construct, was calculated. As Table 6 shows, the Cronbach $\alpha$ coefficient is $0.890(>0.7)$, indicating the high reliability of the questionnaire. 
Table 6. The abstract of fitness degree testing of confirmatory factor analysis. KNO-KaiserMeyer-Olkin.

\begin{tabular}{ccc}
\hline Assessment Items & Recommended Value & Testing Results \\
\hline KMO value & The analyses of reliability and validity & \\
Bartlett's test & $>0.6$ & 0.944 \\
Common factor variance ratio & Significance level $<0.05$ & 0 \\
Crcumulated variance contribution rate & $>0.2$ & $0.428-0.821$ \\
Cronbach $\alpha$ coefficient & $>60 \%$ & 0.89 \\
& $>0.7$ & \\
Chi-square = 361.249; degrees of freedom (DOF) $=146$; probability level $=0.000$ \\
Chi-square DOF ratio & $<3.00$ & 2.474 \\
Indexes of fitness degree & 0.048 \\
RMR (root mean square residual) value & $<0.05$ & 0.837 \\
GFI (goodness-of-fit index) value & $>0.90$ & 0.927 \\
IFI (incremental fit index) value & $>0.90$ & 0.913 \\
TLI (Tacker-Lewis index) value & $>0.90$ & 0.926 \\
CFI (comparative fit index) value & $>0.90$ & 0.643 \\
PGFI (parsimony goodness-of-fit index) value & $>0.50$ & 0.754 \\
PNFI (parsimony-adjusted normed fit index) value & $>0.50$ & 0.791 \\
PCFI (parsimony comparative fit index) value & $>0.50$ & 102 \\
CN (critical N) value & $>200$ & $640.522<1205.950$ \\
& Theoretical model value $<$ & \\
CAIC (consistent Akaike information criterion) value & independent model value & $640.522<3196.94$ \\
& Theoretical model value $<$ &
\end{tabular}

According to the report derived by Amos Output, when the degrees of freedom is 146, the chi-square value is 361.249 , the chi-square degree of freedom ratio is $2.474<3.000$, and the significance probability value is $p=0.00<0.05$. According to the analysis of the other overall fitness indicators, the RMR value is $0.048<0.05$, GFI value is 0.837 , TLI value is 0.913 , CFI value is 0.926 , IFI value is $0.927, \mathrm{CN}$ value is 102 , PGFI value is 0.643 , PNFI value is 0.754 , and PCFI value is 0.791 , indicating an ideal fit of the overall model. The CAIC value of the theoretical model is equal to 640.522 , less than the CAIC value of the saturated model (=1205.950) and less than the CAIC value of the independent model (=3196.94), reaching the acceptable standard of the model. As a whole, the chi-square value is affected by the number of estimated parameters, and the $p$-value is $<0.05$. However, from the perspective of the major fitness statistics, both of them are within the acceptable range; there, it can be judged that the hypothesis model and data have a high fitness, which is suitable for the next multi-group analysis.

\subsection{Testing the Research Hypotheses}

\subsubsection{Test of the Trust Mechanism Model}

The AMOS 24.0 software was used to verify the internal relationship between IT, IPT, and PT, that is, to analyze hypothesis $\mathrm{H} 1, \mathrm{H} 2$, and $\mathrm{H} 3$. The method of parameter estimation was adopted for the maximum likelihood estimation. The coefficients and their $p$-value on the structural model, and the coefficients of determination $\left(\mathrm{R}^{2}\right)$ for the dependent construct are shown in Table 7.

Table 7. Standardized regression weights: group number 1-default model.

\begin{tabular}{cccccc}
\hline No. & Hypotheses & $\begin{array}{c}\text { C.R. } \\
\text { (Critical Ratio) }\end{array}$ & $\begin{array}{c}\text { Path } \\
\text { Coefficient }\end{array}$ & $\mathbf{R}^{2}$ & $\begin{array}{c}\text { Is the Research } \\
\text { Hypotheses } \\
\text { Supported? }\end{array}$ \\
\hline $\mathrm{H} 1$ & $\begin{array}{c}\text { Institutional trust has a positive and significant } \\
\text { impact on product trust. }\end{array}$ & 6.766 & 0.822 & 0.676 & $* * *$ \\
$\mathrm{H} 2$ & $\begin{array}{c}\text { Product trust has a positive and significant } \\
\text { impact on interpersonal trust. }\end{array}$ & 7.106 & 0.762 & 0.892 & $* * *$ \\
$\mathrm{H} 3$ & $\begin{array}{c}\text { Institutional trust has a positive and significant } \\
\text { impact on interpersonal trust. }\end{array}$ & 2.14 & 0.213 & 0.892 & 0.032 \\
\hline
\end{tabular}

*** Significant at 0.001 level. 
The results show that hypotheses $\mathrm{H} 1, \mathrm{H} 2$, and $\mathrm{H} 3$ all reach significant levels, indicating that all of the hypotheses are valid. The values of $R^{2}$ show that the reliability of the measurement index is good. Take 'institutional trust $\rightarrow$ product trust' as an example, its standardized regression coefficient is 0.822 , which means that the direct effect that institutional trust has on product trust is 0.822 , thus, institutional trust carries a high level of relative importance in a product trust; the standardized regression coefficient of 'institutional trust $\rightarrow$ interpersonal trust' is 0.213 , which means that the direct effect of institutional trust to interpersonal trust is relatively low. The standardized regression coefficient of 'product trust $\rightarrow$ interpersonal trust' is 0.762 , indicates that the product trust has a significant impact on interpersonal trust.

\subsubsection{Test of the Hypotheses That Take Cultural Value Factors and Demographics as Moderators}

To test the hypotheses dealing with the effect of cultural values on the model, the AMOS's multi-group analysis module was used to verify each of the hypotheses. In line with reality, the values of the various variables corresponding to the sample of every latent variable of the cultural factors were averaged, then, the samples were divided into two groups (i.e., high PDI and low PDI groups; high and low UAI groups; group with high IDV and low IDV; high MAS and low MAS group; and high and low LTO groups) by the median of the means. The 'gender' group is divided into male and female, and the 'age' group is divided into a youth group $(\leq 25)$ and middle-aged group $(>25)$. The 'education degree' group is divided into college and graduate levels, and the 'disposable income' is divided into ordinary $(\leq 3000 \mathrm{RMB})$ and good $(>3000)$. After that, model A was set unconstrained with all of the parameters being freely estimated; model B is constrained, the constraint term of which is the two conditions when the measurement coefficient equals the structure coefficient, and $\mathrm{A}$ and $\mathrm{B}$ are the control models. After a multiple-group analysis, the difference of the chi-square value is less than 0.05 , indicating that the potential variable has a moderating effect on the hypothesis model. Furthermore, the significant $p$-value and normalization regression coefficient of the two groups of the different hypothesis paths can determine whether the hypothesis is valid, and whether the influence direction is aligned with the research hypotheses.

Table 8 shows that $p$-value of the chi-square value difference in the nested model comparison is $0.001<0.05$, which indicates that the PDI has a moderate effect on the relationships between institutional trust and product trust. Moreover, it is found in Table 9 that the influence direction of H1a is identical with the research hypothesis. The influence direction of H2a is opposite to the research hypothesis, that is, the greater the power distance is, the stronger the influence relationship between the product trust and interpersonal trust is. The significant $p$-value of H3a in the two groups is greater than 0.05 , which indicates that hypothesis $\mathrm{H} 3 \mathrm{a}$ is not valid, that is, the relationship between institutional trust and interpersonal trust is not moderated by the power distance.

Table 8. Assuming model unconstrained to be correct.

\begin{tabular}{|c|c|c|c|c|c|c|c|}
\hline \multirow[t]{2}{*}{ Model } & \multirow{2}{*}{$\begin{array}{c}\text { DF } \\
\text { (Degree of } \\
\text { Freedom) }\end{array}$} & \multirow{2}{*}{$\begin{array}{l}\text { CMIN (the } \\
\text { Minimum } \\
\text { Discrepancy) }\end{array}$} & \multirow[t]{2}{*}{$p(<0.05)$} & $\begin{array}{l}\text { NFI (Normed } \\
\text { Fit Index) }\end{array}$ & $\begin{array}{c}\text { IFI } \\
\text { (Incremental } \\
\text { Fit Index) }\end{array}$ & $\begin{array}{l}\text { RFI (Relative } \\
\text { Fit Index) }\end{array}$ & $\begin{array}{c}\text { TLI } \\
\text { (Tacker-Lewis } \\
\text { Index) }\end{array}$ \\
\hline & & & & Delta-1 & Delta-2 & rho-1 & rho2 \\
\hline $\begin{array}{c}\text { Structural } \\
\text { weights }\end{array}$ & 19 & 43.309 & 0.001 & 0.013 & 0.014 & 0.001 & 0.001 \\
\hline
\end{tabular}

Table 9. Standardized regression weights (unconstrained). PDI-power distance.

\begin{tabular}{|c|c|c|c|c|}
\hline No. & $\begin{array}{l}\text { Estimate } \\
\text { (Low PDI) }\end{array}$ & $\begin{array}{l}\text { Estimate } \\
\text { (High PDI) }\end{array}$ & $\Delta$ Estimate & $\begin{array}{l}\text { Whether the Influence Direction is } \\
\text { Identical with the Research Hypotheses }\end{array}$ \\
\hline H1a & $0.832 * * *$ & $0.786^{* * *}$ & -0.046 & Yes \\
\hline $\mathrm{H} 2 \mathrm{a}$ & $0.688^{* * *}$ & $0.832 * * *$ & 0.144 & No \\
\hline Н3а & $p>0.05$ & $p>0.05$ & & $>0.05$, The hypothesis is invalid \\
\hline
\end{tabular}


Following the same method, six pairwise comparisons of the model for 18 hypotheses were tested. Because of the limitation of the paper's length, we only report the detailed test results of the verification of hypotheses H1a-H1e of the PDI, which is shown in Tables 8 and 9 (detailed test data can be provided upon request).

As illustrated in Table 10, the demographic variables (gender, age, education level, and individual economic level) do not have any moderate effect in the hypotheses model. In terms of the cultural value factors, as Figure 2 shows, the influence of IT on IPT is not moderated by any of the cultural dimensions. While, the influence of IT on PT is moderated by PDI, IDV, UAI, and LTO, and the higher the PDI, IDV, UAI, or LTO are, the weaker the influence will be. Moreover, the relationships between PT and IPT are adjusted by PDI, IDV, and UAI. When the PDI gets higher, the influence of PT on IPT will become stronger. The same thing happens when the individualism or uncertainty avoidance gets lower.

Table 10. Standardized regression weights: group number 1 -default model.

\begin{tabular}{ccc}
\hline Number & Significance & $\begin{array}{c}\text { Whether the Influence Direction is } \\
\text { Identical to the Research Hypotheses }\end{array}$ \\
\hline H1a & Significant & Yes \\
H1b & Significant & Yes \\
H1c & Significant & Yes \\
H1d & Significant & Nos \\
H1e & & No \\
H2a & Significant & Yes \\
H2b & Significant & Yes \\
H2c & Significant & Non-significant \\
H2d & & Non-significant \\
H2e & & Non-significant \\
H3a & & Non-significant \\
H3b & & Non-significant \\
H3c & & Non-significant \\
H3d & & Non-significant \\
H3e & & Non-significant \\
H4 & & Non-significant \\
H5 & & Non-significant \\
H6 & &
\end{tabular}

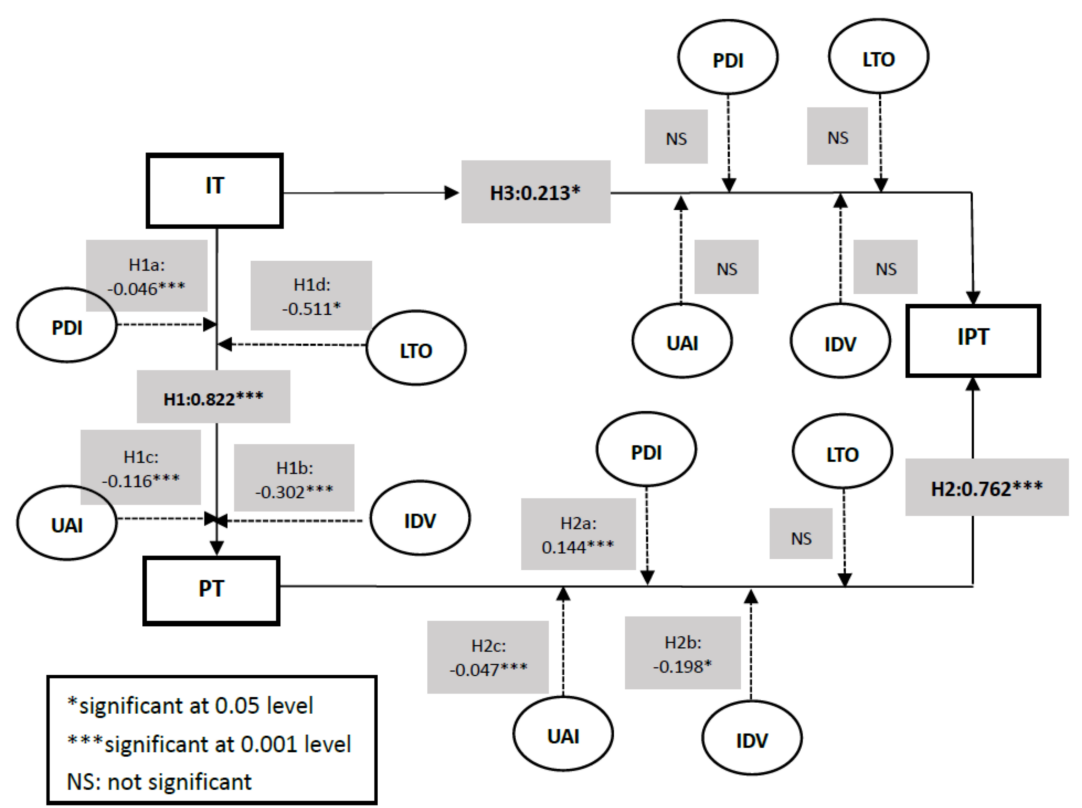

Figure 2. Path diagram for the research model. 


\section{Discussions}

Figure 2 shows that all of the hypotheses of the trust-building mechanism, H1, H2, and H3, are supported. That is, the institutional trust has a significant positive impact on product trust (0.822) and interpersonal trust (0.213), and product trust has a significant positive impact on interpersonal trust (0.762). The trust-building model linked by three modes is established with a relationship between each other. As IT has a significant effect on PT and IPT, in agreement with Xie et al. (2016) [58], we can see that institutional trust is the basis for establishing the initial trust in the sharing economy. Notably, IT has a stronger effect on PT than on IPT, indicating that the sound institutional norms positively influence the customers' trust in the quality of the product more than the interpersonal interactions, which is highly dependent on the participants' individual attributes. This finding can be related to the fact that China may provide one of the most favorable policy environments in the world for now, which in practice has enhanced the customers' IT and effectively helped to build the trust in the sharing economy. Moreover, PT has a significant effect on IPT, indicating that customers' trust in products takes precedence over their trust in interpersonal communications, which suggests that Airbnb practitioners should put more emphasis on improving housing supply quality and service quality.

The hypothesis verification of cultural factors as moderators shows that cultural value dispositions have a significant impact on the trust-building mechanism of Airbnb in several ways. Firstly, the relationships between IT and PT are negatively moderated by PDI, IDV, UAI, and LTO. Moreover, the effect of PT on IPT is positively moderated by PDI, but negatively moderated by IDV and UAI. Verifying that the national culture impacts trust in the e-commerce environment also applies in the sharing economy context, even though not all of the hypotheses were supported by this study. Secondly, we notice that IDV is the most influential cultural value dimension affecting the relationships within the trust-building system. It negatively moderates the influence of IT on PT, and PT on IPT. Culture theorists indicated that people with a low individualist orientation will typically show trust towards their in-group members rather than out-group members and unfamiliar members $[25,70]$. Therefore, the lower the IDV is, the stronger the relationship effect of IT on PT, as individuals with a low individualism tendency would develop trust more in an institutional (group) arrangement rather than on products, which involve more independent thinking and judgement, and the decision-making processes are largely influenced by norms [21]. This finding is consistent with the findings of Yooh (2009) and Hallikainen et al. (2018) [65,67]. Furthermore, this finding may partly explain the wide acceptance of the sharing economy in China, as typical Chinese people tend to have a low individualism disposition [79] that would strengthen the impact IT on PT, and PT on IPT, which makes trust-building in the sharing economy more effective in China. Thirdly, UAI and PDI also have a significant impact on the relationships between IT and PT, PT and IPT. As expected, UAI has a negative impact both on the relationship between IT and PT, PT and IPT. According to previous research, the higher the UAI tendency is, the less possibility of using a new product, including online business $[65,67,83]$. Our finding strengthens this conclusion by providing evidence that UAI will not only hinder one mode of trust involved in e-commerce, but will also negatively moderate the influence of one trust mode on the other, which would make the efforts made by the platform to enhance the institutional trust more difficult to be conveyed for trust building for the products. As for PDI, it negatively moderates the effect IT on PT. McKnight (2001) points out that individuals high in power distance respect authority, and evaluate trustworthiness based on an assessment that the store is reliable [44]. Our study's findings agree with this conclusion that the higher PDI tendency the customers have, the less possibility to transfer trust in the institution to that of the product. However, the moderate effect of PDI on the relationship between PT and IPT is in the opposite direction than hypothesized, which is not expected. One possible explanation for this opposite finding is that customers with high PDI tendency might regard interpersonal interactions as a privileged value, thus the higher the PDI, the stronger the relationship between PT and IPT.

Additionally, MAS turns out to have no significant moderating effect on any of the three groups of trust relationships. Masculine cultures are typically more action-oriented, competitive, 
and performance oriented [48]; therefore, we assumed that MAS would weaken the relationship between the three trust modes. However, to our surprise, not only MAS but also another related demographic moderator, gender, does not have any moderating effect on the trust mechanism in Airbnb, even though our sample data shows that females have a much higher level of participation percentage. The reason might be that the difference in the gender-related attributes may impact all of the aspects of trust, such as on the platform, the product, or the host, which has been proven by many studies $[10,21,29]$. Nevertheless, when it comes to the moderating effect of the inherent relationships between these three trust aspects, men and women may have similar perceptions.

\section{Contributions}

This current study provides relevant contributions to theoretical research and practice.

Firstly, based on Zucker's trust model and other trust theories, we developed a three-mode trust-building model in the context of the sharing economy. Trust can help consumers make good decisions even in an asymmetric information situation [32], especially in the traveling sector of the sharing economy, where transactions involve not only online trading, but also face-to-face interaction between strangers, which entails compound risks (monetary, emotional, and personal safety). Therefore, the trust-building mechanism of the sharing economy is much more critical and relates to the sustainability of this newly emerging business model. Scholars, such as Ufford (2015), Ert (2016), Zervas (2015), and $\mathrm{Wu}$ (2017), investigate how ratings, policies of the platforms, and participants' attributes influence the trustworthiness of the short-term rental model $[10,15,29,30]$, which provide inspiring insights and evidence of what factors really matter in forming participants faith or trust on the P2P short-term rental business. We contribute to the existing literature by categorizing trust in the sharing economy into three major modes, based on Zucker's theory, and incorporating the three modes (IT, IPT, and PT) of trust-building within one model. Furthermore, we illustrate the inherent relationship between these three modes, which helps to comprehend how the three aspects of trust interact with each other and eventually understand the mechanism of gradual accumulation of trust in the transaction process of the sharing economy.

Secondly, we incorporate national cultural value dimensions as moderators in the model to testify how cultural value dispositions impact the trust-building mechanism. The result showed that cultural value dispositions affect the mechanism of trust-building in the sharing economy. In particular, IDV, UAI, and PDI are the three most important cultural dimensions, which have significant moderating effects on the influence that IT has on PT, as well as the effect that PT has on IPT. Unlike previous research, such as Yooh (2009), Srit et al. (2006), Liu et al. (2018), and Hallikainen et al. (2018), who focused on whether national culture values affect the consumer's acceptance of new economics models or technology $[21,65,67,71]$, our findings suggest that the cultural value dispositions of customers would strengthen or weaken the mechanisms for trust-building in the sharing economy.

Thirdly, the sharing economy originated in the Western society, and most of the research has been conducted in Western regions [18], while less attention has been given to emerging countries. This current study might be the first to investigate the effect of cultural traits at the individual level on the trust-building mechanism with data collected in China. The findings may help to explain the rapid growth of the sharing economy practice in China, which can be valuable in the sustainable development of this model in East-Asian countries, where cultural values have similar dispositions.

There are some managerial implications that can be inferred from this study.

(1) To make the model of the sharing economy sustainable, governments, practitioners, and potential users should realize that the trust-building mechanism of this new business model is a systematic task, which requires multiple parties' efforts (including governments, enterprises, and users). Therefore, the governments and practitioners should encourage positive interactions and build trust communities, because sharing begins with the interaction of resource owners, resource users, and platforms, and the positive performance of three-party participation and interaction accelerates the establishment of trust in the sharing economy. 
(2) Institution trust is the first step to establishing initial trust in the sharing economy. The sharing platform should implement security policies and privacy protection policies, and governments should provide a structural guarantee for sharing, such as issuing a corresponding incentive policy, evaluating the operation qualification of the platforms, and authorizing the relevant departments to give credible certification.

(3) As it is reflected in the research, the higher the level of trust that consumers have in the product, the easier it will be for the consumers to interact with their hosts, thereby generating interpersonal trust. Hence, to increase the consumers' confidence in short-term rental platforms like Airbnb, hosts should do more to improve home-stay facilities and service quality, and provide more quality related information to promote trust building. At the same time, effective protection of the privacy and security of the individuals who share the information is also very important. Resource providers like hosts often need to display more personal information to facilitate trust building, which requires the platform to balance information transparency with privacy protection.

(4) Findings from this study show that different cultural value dispositions influence trust-building mechanisms in the sharing economy, and practitioners should be conscious of these differences, especially conducting the sharing business in countries and regions where cultural values are significantly different. For example, in high IDV countries/regions, where consumers have the habit and ability to think independently, the trust-building in the sharing economy will take more efforts, because IDV has a negative moderating effect for IT on PT, which weakens the positive impact that IT originally had on PT. As such, enterprises should put forth more effort to build trust in the sharing economy in countries that possess high levels of IDV, such as the United States, the United Kingdom, and Australia. While, on the other hand, market penetration in countries with typical collectivism disposition, such as China and South Korea, may turn out to be faster, because the trust-building can be more effectively in these societies.

\section{Conclusions}

This study introduces a model of trust building in the sharing economy that incorporates three modes of trust (IT, IPT, and PT) based on Zucker's trust production model. Moreover, we investigated the inherent mechanism of trust-building and the moderating effect that cultural values might have, by using the data collected from Chinese Airbnb consumers through a questionnaire based on the structural equation modeling. As a result, in the Airbnb trust-building mechanism, IT has a positive significant influence on both PT and IPT, so does PT to IPT. The AMOS multi-group analysis shows that demographic variables such as gender, age, education degree, and personal economic level have no moderating effect on the trust mechanism in the Airbnb platform. Regarding cultural variables, the relationship between IT and PT is negatively moderated by PDI, IDV, UAI, and LTO. The relationship between PT and IPT is moderated by PDI, IDV, and UAI. These findings will help governments and practitioners to design policies and strategies to foster the heathy trust communities on sharing economy platforms to reduce the complexity and uncertainty brought about by the nature of the sharing economy, thereby attracting more people to participate in this new business practice and to promote sustainable development. Also, this study of the cultural values' moderating the effects of fostering trust in sharing economy platforms can serve as a reference for the worldwide sustainable development of the sharing economy in different cultural environment.

However, this study has a few limitations. Firstly, we adopted Zucker's three-mode trust production model as our basic model, focusing on investigating the inherent interaction between the three modes of trust, but neglected antecedent variables on trust-building. More antecedent variables, such as the individual's attributes of participants in the sharing economy and new marketing channels (mobile apps), should be considered in this model in the future. Secondly, this study was conducted from the perspective of consumers only, however the sharing economy is a typical two-sided market; and platforms should consider how to attract more hosts as well as consumers. Therefore, researchers can explore trust-building mechanisms by adopting the hosts' perspectives. Thirdly, the sample 
size we used is relatively small, which can be enlarged in the future, to make the conclusion more representative and generalizable. Furthermore, regarding the culture constructs, this paper follows Hofstede's national cultural values, but the subject of religion and how it affects the trust-building and the performance of the short-term rental business is also worthy of studying in the future.

Author Contributions: X.W. and J.S. authored the paper and designed the survey. X.W. led the research design and gave guidance throughout the research process and contributed to the writing and majority of revision. J.S. contributed to the writing of the paper and conducted the survey and data analysis.

Funding: This work was supported by the National Natural Science Foundation of China (Grant No. 71774029)

Conflicts of Interest: The authors declare no conflict of interest.

\section{Appendix A}

Questionnaire on the Evaluation of Airbnb's Trust Mechanism

Part One: Personal information

1. Your nationality:

2. Your gender: $\square$ Male $\square$ Female

3. Your age: $\square \leq 25 \square 26-35 \square 36-45 \square \geq 45$

4. Your education background: $\square$ Junior college and below $\square$ Undergraduate $\square$ Master $\square$ Doctor

5. Your disposable income per month: $\square \leq \$ 150 \square \$ 150-500 \square \$ 500-850 \square \geq \$ 850$

Part Two: In order to understand your cultural values, please choose your consent to the following statements, according to the actual ideas.

\begin{tabular}{|c|c|c|c|c|c|c|}
\hline No. & Description & $\begin{array}{l}\text { Strongly } \\
\text { Agree }\end{array}$ & Agree & Neutral & Disagree & $\begin{array}{l}\text { Strongly } \\
\text { Disagree }\end{array}$ \\
\hline PDI1 & $\begin{array}{l}\text { The social class differences caused by } \\
\text { power and wealth is normal }\end{array}$ & 5 & 4 & 3 & 2 & 1 \\
\hline PDI2 & $\begin{array}{c}\text { We should reduce or eliminate the gap } \\
\text { between power and status }\end{array}$ & 5 & 4 & 3 & 2 & 1 \\
\hline UAI1 & $\begin{array}{c}\text { You are more accustomed to a regular } \\
\text { pattern of work rather than a new } \\
\text { change }\end{array}$ & 5 & 4 & 3 & 2 & 1 \\
\hline UAI2 & $\begin{array}{l}\text { You can easily feel anxious or frightened } \\
\text { in a strange environment }\end{array}$ & 5 & 4 & 3 & 2 & 1 \\
\hline IDV1 & $\begin{array}{c}\text { We should concern ourselves with } \\
\text { collective interests rather than personal } \\
\text { interests. }\end{array}$ & 5 & 4 & 3 & 2 & 1 \\
\hline IDV2 & $\begin{array}{l}\text { Everyone is totally independent and } \\
\text { different from other people }\end{array}$ & 5 & 4 & 3 & 2 & 1 \\
\hline MAS1 & $\begin{array}{l}\text { Men always do better than women in } \\
\text { some jobs. }\end{array}$ & 5 & 4 & 3 & 2 & 1 \\
\hline MAS2 & $\begin{array}{l}\text { We should devote ourselves to building } \\
\text { a harmonious social relationship. }\end{array}$ & 5 & 4 & 3 & 2 & 1 \\
\hline LTO1 & $\begin{array}{l}\text { There should be a long-term plan for } \\
\text { everything. }\end{array}$ & 5 & 4 & 3 & 2 & 1 \\
\hline LTO2 & $\begin{array}{l}\text { You care more about the future than } \\
\text { your immediate interests. }\end{array}$ & 5 & 4 & 3 & 2 & 1 \\
\hline
\end{tabular}

Part Three: In combination with the experiences or understanding of Airbnb, please choose your consent to the following statements, according to the actual ideas. 


\begin{tabular}{|c|c|c|c|c|c|c|}
\hline No. & Description & $\begin{array}{l}\text { Strongly } \\
\text { Agree }\end{array}$ & Agree & Neutral & Disagree & $\begin{array}{l}\text { Strongly } \\
\text { Disagree }\end{array}$ \\
\hline IT1 & I think Airbnb has a good reputation & 5 & 4 & 3 & 2 & 1 \\
\hline IT2 & $\begin{array}{l}\text { I would browse the description of the } \\
\text { house and the previous reviews }\end{array}$ & 5 & 4 & 3 & 2 & 1 \\
\hline IT3 & $\begin{array}{l}\text { I am not sensitive to the risks in } \\
\text { accommodation transaction }\end{array}$ & 5 & 4 & 3 & 2 & 1 \\
\hline IT4 & $\begin{array}{l}\text { I will not take the initiative in referring } \\
\text { to the terms and policies of Airbnb }\end{array}$ & 5 & 4 & 3 & 2 & 1 \\
\hline IPT1 & $\begin{array}{l}\text { During the stay, the host should fulfill } \\
\text { his service commitments }\end{array}$ & 5 & 4 & 3 & 2 & 1 \\
\hline IPT2 & $\begin{array}{c}\text { The host and renter should not reveal } \\
\text { their mutual privacy }\end{array}$ & 5 & 4 & 3 & 2 & 1 \\
\hline IPT3 & $\begin{array}{l}\text { The host is gracious and polite, which } \\
\text { makes me happy. }\end{array}$ & 5 & 4 & 3 & 2 & 1 \\
\hline IPT4 & $\begin{array}{l}\text { The host should answer my question in } \\
\text { time }\end{array}$ & 5 & 4 & 3 & 2 & 1 \\
\hline IPT5 & $\begin{array}{c}\text { The host's active care will make me } \\
\text { happy. }\end{array}$ & 5 & 4 & 3 & 2 & 1 \\
\hline IPT6 & $\begin{array}{l}\text { I like to interact with my host and even } \\
\text { become friends. }\end{array}$ & 5 & 4 & 3 & 2 & 1 \\
\hline PT1 & I care about the decor of the room & 5 & 4 & 3 & 2 & 1 \\
\hline PT2 & I care about the comfort of the room & 5 & 4 & 3 & 2 & 1 \\
\hline PT3 & $\begin{array}{l}\text { I care if the facilities in the room are } \\
\text { complete. }\end{array}$ & 5 & 4 & 3 & 2 & 1 \\
\hline PT4 & I care about the sanitation in the room & 5 & 4 & 3 & 2 & 1 \\
\hline PT5 & $\begin{array}{l}\text { I care about the soundproof effect of the } \\
\text { room }\end{array}$ & 5 & 4 & 3 & 2 & 1 \\
\hline PT6 & $\begin{array}{c}\text { I care about the traffic conditions around } \\
\text { the house }\end{array}$ & 5 & 4 & 3 & 2 & 1 \\
\hline PT7 & $\begin{array}{l}\text { I would choose a house with good } \\
\text { public security }\end{array}$ & 5 & 4 & 3 & 2 & 1 \\
\hline PT8 & $\begin{array}{l}\text { I will choose a house that is prosperous } \\
\text { and bustling around me. }\end{array}$ & 5 & 4 & 3 & 2 & 1 \\
\hline PT9 & $\begin{array}{l}\text { I will choose a house that has many } \\
\text { tourism attractions around me. }\end{array}$ & 5 & 4 & 3 & 2 & 1 \\
\hline
\end{tabular}

\section{References}

1. Belk, R. Sharing. J. Consum. Res. 2009, 36, 715-734. [CrossRef]

2. Kang, S.; Na, Y.K. The Effect of the Relationship Characteristics and Social Capital of the Sharing Economy Business on the Social Network, Relationship Competitive Advantage, and Continuance Commitment. Sustainability 2018, 10, 1-22. [CrossRef]

3. Rifkin, J. The Zero Marginal Cost Society: The Internet of Things, the Collaborative Commons, and the Eclipse of Capitalism; St. Martin's Press: New York, NY, USA, 2014.

4. Heinrichs, H. Sharing economy: A potential new pathway to sustainability. GAIA-Ecol. Perspect. Sci. Soc. 2013, 22, 228-231. [CrossRef]

5. Botsman, R.; Rogers, R. What's Mine Is Yours: The Rise of Collaborative Consumption; Harper Collins e-books: New York, NY, USA, 2010.

6. Hamari, J.; Sjöklint, M.; Ukkonen, A. The sharing economy: Why people participate in collaborative consumption. J. Assoc. Inf. Sci. Technol. 2016, 67, 2047-2059. [CrossRef]

7. Schor, J.B.; Fitzmaurice, C.J. 26. Collaborating and connecting: The emergence of the sharing economy. In Handbook of Research on Sustainable Consumption; Edward Elgar Publishing: Cheltenham, UK, 2015; p. 410.

8. Martin, E.W.; Shaheen, S.A. Greenhouse Gas Impacts of Car Sharing in North America. In Mineta Transportation Institute Report 09-11; Mineta Transportation Institute: San Jose, CA, USA, 2010.

9. Sundararajan, A. From Zipcar to the sharing economy. Harv. Bus. Rev. 2013. Available online: https: / /hbr.org/2013/01/from-zipcar-to-the-sharing-eco (accessed on 20 August 2018).

10. Zervas, G.; Proserpio, D.; Byers, J.W. The rise of the sharing economy: Estimating the impact of Airbnb on the hotel industry. J. Mark. Res. 2017, 54, 687-705. [CrossRef] 
11. Brescia, R.H. Regulating the Sharing Economy: New and Old Insights into an Oversight Regime for the Peer-to-Peer Economy. Neb. Law Rev. 2016, 95, 1-69.

12. Koopman, C.; Mitchell, M.; Thierer, A. The Sharing Economy and Consumer Protection Regulation: The Case for Policy Change. J. Bus. Entrep. Law 2015, 8, 529. [CrossRef]

13. Cohen, M.; Sundararajan, A. Self-Regulation and Innovation in the Peer-to-Peer Sharing Economy. Univ. Chic. Law Rev. Online 2015, 82, 116.

14. Nuñez-Cacho, P.; Górecki, J.; Molina-Moreno, V.; Corpas-Iglesias, F.A. What is measured is done: Development of a circular scale measuring the economy for the construction industry. Sustainability 2018, 10, 2340. [CrossRef]

15. Wu, J.; Ma, P.; Xie, K.L. In sharing economy we trust: The effects of host attributes on short-term rental purchases. Int. J. Contemp. Hosp. Manag. 2017, 29, 2962-2976. [CrossRef]

16. Schor, J.B. Plenitude: The New Economics of True Wealth; Penguin Press: New York, NY, USA, 2010.

17. Gansky, L. The Mesh: Why the Future of Business Is Sharing; Penguin: New York, NY, USA, 2010.

18. Cheng, M. Sharing economy: A review and agenda for future research. Int. J. Hosp. Manag. 2016, 57, 60-70. [CrossRef]

19. PricewaterhouseCoopers. Customer Intelligence Series: The Sharing Economy, 18 April 2015. Available online: http:/ / www.pwc.com/us/en/industry/entertainment-media/publications / consumer-intelligenceseries/assets/pwc-cis-sharing-economy.pdf (accessed on 5 April 2017).

20. Lee, C. Airbnb Sees China as Its Number One Market by 2020. Available online: https:/ /www.zdnet.com/article/ airbnb-sees-china-as-its-number-one-market-by-2020,2017-12-10/2018-07-31 (accessed on 1 August 2018).

21. Liu, Y.; Yang, Y. Empirical Examination of Users' Adoption of the Sharing Economy in China Using an Expanded Technology Acceptance Model. Sustainability 2018, 10, 1262. [CrossRef]

22. General Office of the State Council. Guidance on Promoting Holistic Tourism Destinations Development. Available online: http:/ / www.gov.cn/gongbao/content/2018/content_5280575.htm (accessed on 1 August 2018).

23. Retail \& Ecommerce. Airbnb's Troubles in Spain Grow Alongside Greater Use. Available online: https:/ / www.emarketer.com/Article/Airbnbs-Troubles-Spain-Grow-Alongside-Greater-Use/ 1015323,2017-02-28 (accessed on 1 August 2018).

24. PConline. The Local Government in Detroit has Quietly Imposed a Ban on Airbnb Rentals. Available online: http:/ / pcedu.pconline.com.cn/1083/10835553.html,2018-02-12 (accessed on 1 August 2018).

25. Fukuyama, F. Trust: The Social Virtues and the Creation of Prosperity; Free Press Paperbacks: New York, NY, USA, 1995.

26. Doney, P.M.; Cannon, J.P.; Mullen, M.R. Understanding the influence of national culture on the development of trust. Acad. Manag. Rev. 1998, 23, 601-620. [CrossRef]

27. Bjørnskov, C. Determinants of generalized trust: A cross-country comparison. Public Choice 2007, 130, 1-21. [CrossRef]

28. Cyr, D. Website design, trust and culture: An eight country investigation. Electron. Commer. Res. Appl. 2013, 12, 373-385. [CrossRef]

29. Ert, E.; Fleischer, A.; Magen, N. Trust and reputation in the sharing economy: The role of personal photos in Airbnb. Tour. Manag. 2016, 55, 62-73. [CrossRef]

30. Ufford, S. The Future of the Sharing Economy Depends on Trust. Forbes, 2015. Available online: http:// www.forbes.com/sites/theyec/2015/02/10/the-future-of-the-sharing-economydepends-on-trust (accessed on 9 October 2017).

31. Finley, K. Trust in the Sharing Economy: An Exploratory Study; Centre for Cultural Policy Studies; University of Warwick: Coventry, UK, 2013.

32. Zucker, L.G. Production of trust: Institutional sources of economic structure, 1840-1920. Res. Organ. Behav. 1986, 8, 53-111.

33. Palos-Sanchez, P.R.; Correia, M.B. The Collaborative Economy Based Analysis of Demand: Study of Airbnb Case in Spain and Portugal. J. Theor. Appl. Electron. Commer. Res. 2018, 13, 85-98. [CrossRef]

34. Bardhi, F.; Eckhardt, G.M. Access-based consumption: The case of car sharing. J. Consum. Res. 2012, 39, 881-898. [CrossRef]

35. Ritzer, G.; Jurgenson, N. Production, consumption, prosumption: The nature of capitalism in the age of the digital 'prosumer'. J. Consum. Cult. 2010, 10, 13-36. [CrossRef] 
36. Tussyadiah, I.P. Factors of satisfaction and intention to use peer-to-peer accommodation. Int. J. Hosp. Manag. 2016, 55, 70-80. [CrossRef]

37. Sigala, M. Collaborative commerce in tourism: Implications for research and industry. Curr. Issues Tour. 2017, 20, 346-355. [CrossRef]

38. Piscicelli, L.; Cooper, T.; Fisher, T. The role of values in collaborative consumption: Insights from a product-service system for lending and borrowing in the UK. J. Clean. Prod. 2015, 97, 21-29. [CrossRef]

39. Stors, N.; Kagermeier, A. Motives for Using Airbnb in Metropolitan Tourism-Why do People Sleep in the Bed of a Stranger? Reg. Mag. 2015, 299, 17-19. [CrossRef]

40. Rogers, K. Hosts Generated $\$ 500$ Million a Year on Airbnb: Study. Consumer News and Business Channel. 2016. Available online: http:/ /www.cnbc.com/2016/01/20/hosts-generated-500-million-a-year-on-airbnbstudy.html (accessed on 23 July 2017).

41. Glaeser, E.L.; Laibson, D.I.; Scheinkman, J.A.; Soutter, C.L. Measuring trust. Q. J. Econ. 2000, 115, $811-846$. [CrossRef]

42. McKnight, D.H.; Chervany, N.L.; Cummings, L.L. Trust formation in new organizational relationships. In Management Information Systems Research Center; Curtis, L., Ed.; Carlson School of Management, University of Minnesota: Minneapolis, MN, USA, 1996.

43. Lewicki, R.J.; Tomlinson, E.C.; Gillespie, N. Models of interpersonal trust development: Theoretical approaches, empirical evidence, and future directions. J. Manag. 2006, 32, 991-1022. [CrossRef]

44. McKnight, D.H.; Chervany, N.L. What trust means in e-commerce customer relationships: An interdisciplinary conceptual typology. Int. J. Electron. Commer. 2001, 6, 35-59. [CrossRef]

45. Morgan, R.M.; Hunt, S.D. The commitment-trust theory of relationship marketing. J. Mark. 1994, 58, $20-38$. [CrossRef]

46. Kumar, N. The power of trust in manufacturer-retailer relationships. Harv. Bus. Rev. 1996, 74, 92.

47. Gefen, D. E-commerce: The role of familiarity and trust. Omega 2000, 28, 725-737. [CrossRef]

48. Schoorman, F.D.; Mayer, R.C.; Davis, J.H. An integrative model of organizational trust: Past, present, and future. Acad. Manag. Rev. 2007, 32, 344-354. [CrossRef]

49. Pavlou, P.A.; Gefen, D. Building effective online marketplaces with institution-based trust. Inf. Syst. Res. 2004, 15, 37-59. [CrossRef]

50. Kim, D.J.; Ferrin, D.L.; Rao, H.R. A trust-based consumer decision-making model in electronic commerce: The role of trust, perceived risk, and their antecedents. Decis. Support Syst. 2008, 44, 544-564. [CrossRef]

51. Weber, T.A. Intermediation in a sharing economy: Insurance, moral hazard, and rent extraction. J. Manag. Inf. Syst. 2014, 31, 35-71. [CrossRef]

52. Hawlitschek, F.; Teubner, T.; Adam, M.T.P.; Borchers, N.S.; Möhlmann, M.; Weinhardt, C. Trust in the sharing economy: An experimental framework. In Proceedings of the Thirty Seventh International Conference on Information Systems (ICIS 2016), Dublin, Ireland, 11-14 December 2016.

53. Joinson, A.N.; Reips, U.D.; Buchanan, T.; Schofield, C.P. Privacy, trust, and self-disclosure online. Human-Comput. Interact. 2010, 25, 1-24. [CrossRef]

54. Mittendorf, C. What Trust means in the Sharing Economy: A provider perspective on Airbnb.com. In Proceedings of the AMCIS 2016, San Diego, CA, USA, 11-14 August 2016.

55. Yoon, H.S.; Occeña, L.G. Influencing factors of trust in consumer-to-consumer electronic commerce with gender and age. Int. J. Inf. Manag. 2015, 35, 352-363. [CrossRef]

56. Gefen, D.; Benbasat, I.; Pavlou, P. A research agenda for trust in online environments. J. Manag. Inf. Syst. 2008, 24, 275-286. [CrossRef]

57. Kamal, P.; Chen, J.Q. Trust in Sharing Economy. In Proceedings of the PACIS 2016, Chiayi, Taiwan, 27 June1 July 2016; p. 109.

58. Xie, X.M.; Shi, J.J. Empiricla Research on formation mechanism of consumer trust in sharing economy. Technol. Econ. 2016, 35, 122-127.

59. Núñez-Cacho, P.; Molina-Moreno, V.; Corpas-Iglesias, F.A.; Cortés-García, F.J. Family Businesses in Transition to a Circular Economy Model: The Case of "Mercadona". Sustainability 2018, 10, 538. [CrossRef]

60. Hofstede, G. Culture's Consequences: International Differences in Work-Related Values; Sage: Newcastle upon Tyne, UK, 1984.

61. Kluckhohn, F.R.; Strodtbeck, F.L. Variations in Value Orientations; Greenwood Press: London, UK, 1961. 
62. Schwartz, S.H.; Verkasalo, M.; Antonovsky, A.; Sagiv, L. Value priorities and social desirability: Much substance, some style. Br. J. Soc. Psychol. 1997, 36, 3-18. [CrossRef]

63. Luthans, F.; Doh, J.P. Cross-cultural Communication and Management, 9th ed.; McGraw-Hill: New York, NY, USA, 2008.

64. Yamagishi, T. The provision of a sanctioning system in the United States and Japan. Soc. Psychol. Q. 1988, 51, 265-271. [CrossRef]

65. Hallikainen, H.; Laukkanen, T. National culture and consumer trust in e-commerce. Int. J. Inf. Manag. 2018, 38, 97-106. [CrossRef]

66. Suh, T.; Kwon, I.W.G. Globalization and reluctant buyers. Int. Mark. Rev. 2002, 19, 663-680. [CrossRef]

67. Yoon, $\mathrm{C}$. The effects of national culture values on consumer acceptance of e-commerce: Online shoppers in China. Inf. Manag. 2009, 46, 294-301. [CrossRef]

68. Jarvenpaa, S.L.; Leidner, D.E. Communication and trust in global virtual teams. Organ. Sci. 1999, 10, 791-815. [CrossRef]

69. Gefen, D.; Heart, T.H. On the need to include national culture as a central issue in e-commerce trust beliefs. J. Glob. Inf. Manag. 2006, 14, 1-30. [CrossRef]

70. Triandis, H.C. The self and social behavior in differing cultural contexts. Psychol. Rev. 1989, 96, 506. [CrossRef]

71. Srite, M.; Karahanna, E. The role of espoused national cultural values in technology acceptance. MIS Q. 2006, 30, 679-704. [CrossRef]

72. Parasuraman, A.; Zeithaml, V.A.; Berry, L.L. SERVQUAL: A Multiple-Item Scale for Measuring Consumer Perceptions of Service Quality. J. Retail. 1998, 1, 12-40.

73. Parasuraman, A.; Zeithaml, V.A.; Malhotra, A. E-S-QUAL: A Multiple-Item Scale for Accessing Electronic Service Quality. J. Serv. Res. 2005, 7, 213-233. [CrossRef]

74. Pavlou, P.A.; Dimoka, A. The Nature and Role of Feedback Text Comments in Online Marketplaces: Implications for Trust Building, Price Premiums, and Seller Differentiation. Inf. Syst. Res. 2006, 17, 392-414. [CrossRef]

75. Zhang, X.; Yang, Y. An Evaluation on Service Quality of B\&B. Industry in China. J. Huzhou Univ. 2017, 39, 59-66.

76. Li, D.; Qiu, F.; Dong, C. Empirical Study on Evaluation System of Bed and Breakfast Resources. World Sci.-Tech. R D 2015, 37, 404-409.

77. Jones, D.; Guan, J.J. Bed and Breakfast Lodging Development in Mainland China: Who is the Potential Customer. Asia Pac. J. Tour. Res. 2011, 16, 517-536. [CrossRef]

78. Gimasekaran, N.; Anandkumar, V. Factors of Influence in Choosing Alternative Accommodation: A Study with Reference to Pondicherry, A Coastal Heritage Town. Procedia-Soc. Behav. Sci. 2012, 62, 1127-1132. [CrossRef]

79. Yang, S.; Ahn, S. Impact of motivation in the sharing economy and perceived security in attitude and loyalty toward Airbnb. Adv. Sci. Technol. Lett. 2016, 129, 180-184.

80. Wu, M. Structural Equation Model-AMOS Operation and Application; Chongqing University Press: Chongqing, China, 2010. (In Chinese)

81. China Tourism Academy, Airbnb China. 2017 Report on The Trend of Sharing Lodging Consumption in China. Available online: http://www.china.com.cn/travel/txt/2017-06/09/content_40995677.htm (accessed on 12 September 2017).

82. Hofstede, G. Culture's Consequences: Comparing Values, Behaviors, Institutions and Organizations Across Nations; Sage Publications: Newcastle upon Tyne, UK, 2003.

83. Leidner, D.E.; Kayworth, T. A review of culture in information systems research: Toward a theory of information technology culture conflict. MIS Q. 2006, 30, 357-399. [CrossRef]

(C) 2018 by the authors. Licensee MDPI, Basel, Switzerland. This article is an open access article distributed under the terms and conditions of the Creative Commons Attribution (CC BY) license (http://creativecommons.org/licenses/by/4.0/). 